\title{
Association between Happiness and Related Psychosocial Correlates and Job Satisfaction among the Employees of Information Technology (IT) Sector: A Comparative Analysis of Gender Difference
}

\author{
Priyankar Singha ${ }^{1}$
}

\section{ABSTRACT}

The present study deals with gender difference in job satisfaction among the employees of Information Technology (IT) sector. Attempts were also made to assess their level of happiness, quality of interpersonal relationship and coping style. The sample size was 50 divided into 2 groups (male- 25 and female- 25). Each group was consisted respondents age ranging between 22-35 years and having minimum 2 years of job experience. The data were collected from several private sectors IT companies of west Bengal. Job satisfaction scale, Oxford happiness inventory, interpersonal relationship inventory and coping checklist II were administered to assess the level of job satisfaction, level of happiness quality of interpersonal relationship and coping style. It is revealed that female employees were found to be more satisfied than male employees in their job and in case of the other variables an opposite result was found. No significant difference between the two gender has been revealed in the selected variables. Furthermore, no significant correlation has been found between job satisfaction and the other selected variables for the present sample. The results of the present study can be fruitful for further research studies.

Keywords: Happiness, Psychosocial Correlates, Job Satisfaction, Gender Difference, IT Sector.

Happiness is a mental or emotional state of well-being defined by positive or pleasant emotions ranging from contentment to intense joy. A variety of biological, psychological, religious, and philosophical approaches have striven to define happiness and identify its sources. Various research groups, including positive psychology, are employing the scientific method to research questions about what "happiness" is, and how it might be attained. Philosophers and religious

\footnotetext{
${ }^{1}$ Ph.D, Research Scholar, Department of psychology, Calcutta university, Kolkata, India *Responding Author

(C) 2016, P Singha; licensee IJIP. This is an Open Access Research distributed under the terms of the Creative Commons Attribution License (http://creativecommons.org/licenses/by/2.0), which permits unrestricted use, distribution, and reproduction in any Medium, provided the original work is properly cited.
} 


\section{Association between Happiness and Related Psychosocial Correlates and Job Satisfaction among the Employees of Information Technology (IT) Sector: A Comparative Analysis of Gender Difference}

thinkers often define happiness in terms of living a good life, or flourishing, rather than simply as an emotion. Happiness in this sense was used to translate the Greek Eudaimonia, and is still used in virtue ethics. Happiness is a fuzzy concept and can mean many different things to many people. Part of the challenge of a science of happiness is to identify different concepts of happiness, and where applicable, split them into their components. Related concepts are wellbeing, quality of life and flourishing. At least one author defines happiness as contentment (Graham, Michael C. (2014). Some commentators focus on the difference between the hedonistic tradition of seeking pleasant and avoiding unpleasant experiences, and the tradition of living life in a full and deeply satisfying way.

It is always made a conclusion that happiness is closely related to quality of the interpersonal relationship. Close relationships are sometimes called interpersonal relationships. The closest relationships are most often found with family and a small circle of best friends. Interpersonal relationships require the most effort to nurture and maintain. These are also the relationships that give you the most joy and satisfaction. An interpersonal relationship is an association between two or more people that may range from fleeting to enduring. This association may be based on inference, love, solidarity, regular business interactions, or some other type of social commitment. Interpersonal relationships are formed in the context of social, cultural and other influences. The context can vary from family or kinship relations, friendship, marriage, relations with associates, work, clubs, neighbourhoods, and places of worship. They may be regulated by law, custom, or mutual agreement, and are the basis of social groups and society as a whole. A relationship is normally viewed as a connection between individuals, such as a romantic or intimate relationship, or a parent-child relationship. Individuals can also have relationships with groups of people, such as the relation between a pastor and his congregation, an uncle and a family, or a mayor and a town. Finally, groups or even nations may have relations with each other. When in a healthy relationship, happiness is shown and the relationship is now a priority. Interpersonal relationships are dynamic systems that change continuously during their existence. Like living organisms, relationships have a beginning, a lifespan, and an end. They grow and improve gradually, as people get to know each other and become closer emotionally, or they gradually deteriorate as people drift apart, move on with their lives, and form new relationships with others.

An interpersonal relationship is a strong, deep,

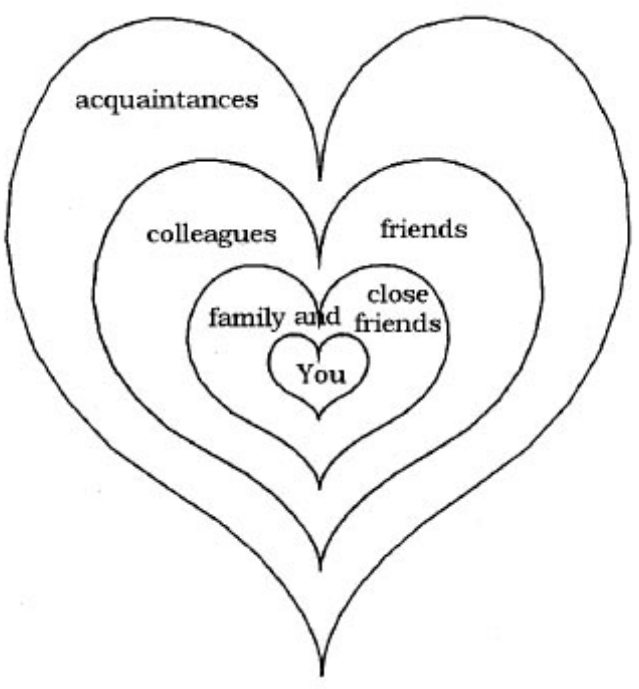
or close association or acquaintance between two 


\section{Association between Happiness and Related Psychosocial Correlates and Job Satisfaction among the Employees of Information Technology (IT) Sector: A Comparative Analysis of Gender Difference}

or more people that may range in duration from brief to enduring. This association may be based on inference, love, solidarity, regular business interactions, or some other type of social commitment. Interpersonal relationships are formed in the context of social, cultural and other influences. The context can vary from family or kinship relations, friendship, marriage, relations with associates, work, clubs, neighbourhoods, and places of worship. They may be regulated by law, custom, or mutual agreement, and are the basis of social groups and society as a whole.

On the several hand coping is an another component that can influence happiness and interpersonal relationship and lots of related psychosocial correlates. Coping is expending conscious effort to solve personal and interpersonal problems, and seeking to master, minimize or tolerate stress or conflict (Weiten, W. \& Lloyd, M.A., 2008). The effectiveness of the coping efforts depend on the type of stress and/or conflict, the particular individual, and the circumstances.

The concept of job satisfaction has been developed in many ways by many different researchers and practitioners. One of the most widely used definitions in organizational research is that of Locke (1976), who defines job satisfaction as "a pleasurable or positive emotional state resulting from the appraisal of one's job or job experiences" (p. 1304) (Locke, E. A. (1976). Others have defined it as simply how content an individual is with his or her job; whether he or she likes the job or not (Spector, P.E. (1997). It is assessed at both the global level (whether or not the individual is satisfied with the job overall), or at the facet level (whether or not the individual is satisfied with different aspects of the job). Spector (1997) lists 14 common facets: Appreciation, Communication, Coworkers, Fringe benefits, Job conditions, Nature of the work, Organization, Personal growth, Policies and procedures, Promotion opportunities, Recognition, Security, and Supervision).

A more recent definition of the concept of job satisfaction is from Hulin and Judge (2003), who have noted that job satisfaction includes multidimensional psychological responses to an individual's job, and that these personal responses have cognitive (evaluative), affective (or emotional), and behavioural components (Hulin, C. L., \& Judge, T. A , 2003). Job satisfaction scales vary in the extent to which they assess the affective feelings about the job or the cognitive assessment of the job. Affective job satisfaction is a subjective construct representing an emotional feeling individuals have about their job. Hence, affective job satisfaction for individuals reflects the degree of pleasure or happiness their job in general induces. Cognitive job satisfaction is a more objective and logical evaluation of various facets of a job. Cognitive job satisfaction can be unidimensional if it comprises evaluation of just one facet of a job, such as pay or maternity leave, or multidimensional if two or more facets of a job are simultaneously evaluated. Cognitive job satisfaction does not assess the degree of pleasure or happiness that arises from specific job facets, but rather gauges the extent to which those job facets are judged 


\section{Association between Happiness and Related Psychosocial Correlates and Job Satisfaction among the Employees of Information Technology (IT) Sector: A Comparative Analysis of Gender Difference}

by the job holder to be satisfactory in comparison with objectives they themselves set or with other jobs. While cognitive job satisfaction might help to bring about affective job satisfaction, the two constructs are distinct, not necessarily directly related, and have different antecedents and consequences (Moorman, R.H, 1993).

Job satisfaction can also be seen within the broader context of the range of issues which affect an individual's experience of work, or their quality of working life. Job satisfaction can be understood in terms of its relationships with other key factors, such as general well-being, stress at work, control at work, home-work interface, and working conditions (Tomaževič, N.; Seljak, J.; Aristovnik, A. 2014). The relationship among the selected variables can be summarized in the following diagram

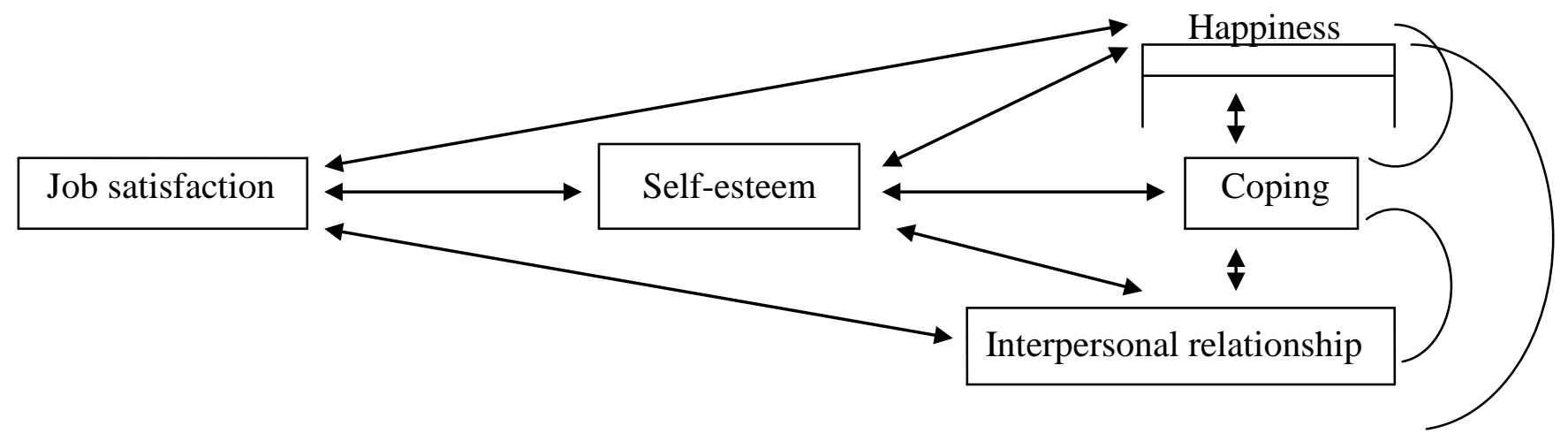

It is very clear that the world is flat due to information technology (IT). IT has agitated the world and brought about worldwide industry. However, based on the systems strategy triangle, a company has to balance its commerce, organizational and information system strategies to be booming. It is, consequently, not amazing that the job satisfaction among the IT employees is leading to the achievement of any commerce of these existence.

Several research being studied in the field of Job Satisfaction, show that there are gender differences in job satisfaction. It has been studied that though women's role at work are lesser in position and pay, they have lesser complains of dissatisfaction at work. Job Satisfaction depends on the job characteristics, family responsibility and personal expectation of the employees (Flarencis et. al, 2010). A lot of studies state that women face greater work load stress leading to a lower overall satisfaction compared to men. There is a significant gender difference seen in time management, organisational support, job pressures and pay and increment (Hodson Randy, 1989). The employees' personality and attitude towards women and their growth in the company matter a lot in experiencing a higher job satisfaction as it will not make a difference in one's job satisfaction if being supervised by a woman (Belsky et.al, 1985). 


\section{Association between Happiness and Related Psychosocial Correlates and Job Satisfaction among the Employees of Information Technology (IT) Sector: A Comparative Analysis of Gender Difference}

There has been a recent interest in exploring factors influencing job satisfaction with a specific focus on gender differences. Clark (1997) used a large-scale survey to test the proposition that men and women in identical jobs should be equally satisfied. Study results reported that the average job for females was lower in stature and income than for males, yet females reported higher levels of job satisfaction. Sousa-Poza and Souza-Poza (2003) report similar findings from a national household panel survey in the Britain. In a study among women working in the private banking sector, Metle (2001) found that job satisfaction declines with increasing levels of education. Metle (2001) argues that higher levels of education tend to increase employee goal and income expectations. Women participating in the study reported gender discrimination in seniority and qualifications.

Men and women working in gender-balanced groups have higher levels of job satisfaction than those who work in homogeneous groups. Employees who work in groups comprised of mostly men tend to show the lowest levels of job satisfaction, and those working in groups of mostly women fall in the middle of the gender-balanced and mostly-men groups (Fields \& Blum, 1997).

Pook, Füstös, and Marian (2003) surveyed 932 employees in Eastern Europe to explore the impact of gender bias on job satisfaction. Results suggest that women are less likely to receive help from their managers toward advancement and are less satisfied than men with the work they performed. This may be the result of being assigned less-challenging tasks, non-commensurate with their backgrounds.

Using data from the U.S. National Study of the Changing Workforce, Bender, Donohue, and Heywood (2005) report that overall women have higher job satisfaction than men and have higher job satisfaction in workplaces dominated by women. However, men and women value job flexibility differently, and once this difference is controlled for, gender composition in the workplace plays no role in determining job satisfaction of women.

Gender difference in Job satisfaction is a major concern for organisations in today's global workforce and has been widely studied throughout Organisational Psychological and Managerial literature. The main purpose of the study is to explore the gender difference in job satisfaction among the employees of IT sector and its relations to their level of happiness, quality of interpersonal relationship and coping style.

\section{RESEARCH METHOD}

\section{Hypothesis:}

1. There is a significant difference between the male and female IT sector employees in level of happiness. 


\section{Association between Happiness and Related Psychosocial Correlates and Job Satisfaction among the Employees of Information Technology (IT) Sector: A Comparative Analysis of Gender Difference}

2. There is a significant difference between the male and female IT sector employees in quality of interpersonal relationship.

3. There is a significant difference between the male and female IT sector employees in coping style.

4. There is a significant difference between the male and female IT sector employees in level of job satisfaction.

5. There is a significant association between happiness and job satisfaction among the IT sector employees.

6. There is a significant association between interpersonal relationship and job satisfaction among the IT sector employees.

7. There is a significant association between coping and job satisfaction among the IT sector employees.

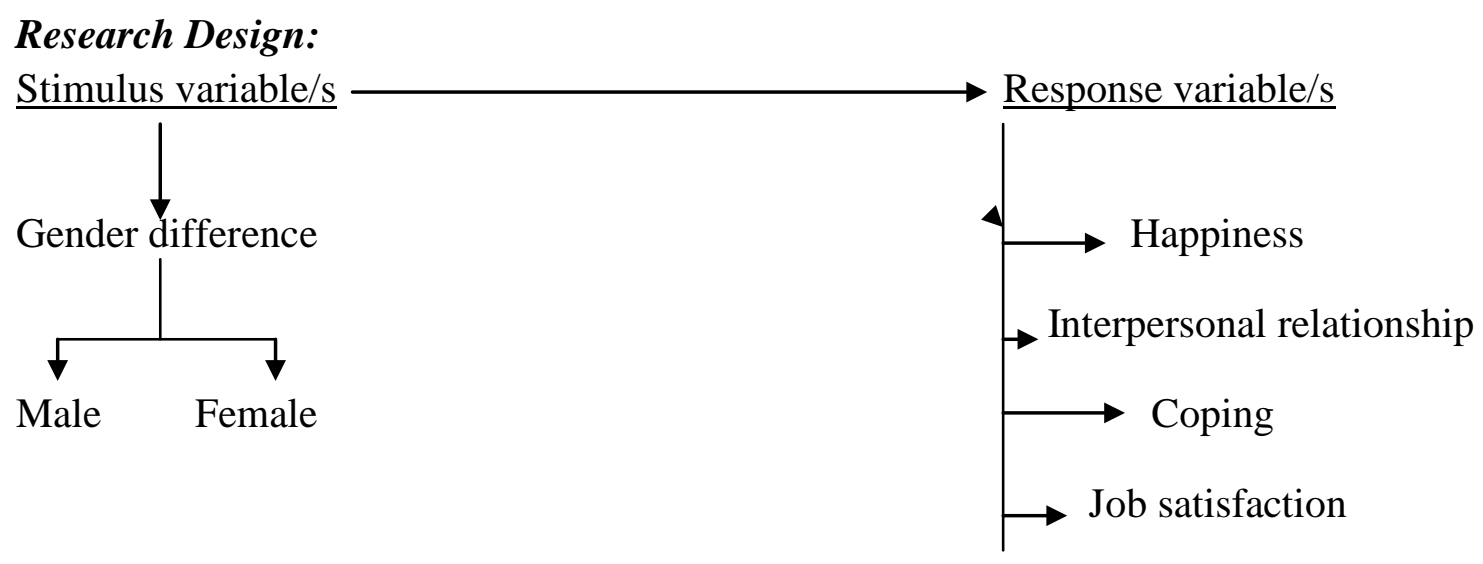

This existing study is descriptive in its nature. Well, descriptive research can be defined as describing some particular situation, some phenomena or something. Descriptive researches are those which define the current situation instead of inferring and making judgments (Creswell, 1994). The core goal of the descriptive research is to verify the developed hypotheses that reveal the current situation. This kind of research offers information about current scenario and emphasis on the elements that effect the job satisfaction. Furthermore, the current research is comparative in nature, evaluating the Gender differences in Job Satisfaction experienced by male and female IT sector employees.

\section{Sample:}

In order to gather data for understanding job satisfaction, a sample of 50 respondents was asked to take part in a self-administered questionnaire. The respondent of the current study was the employees of Information Technology sector. The total size of the sample was 50 and divide into two groups of gender (male- 25, female25). The present research uses a non-probability sampling technique that is convenience sampling. Convenience sampling is a procedure that gains and gathers the appropriate information from the unit of study or sample that are suitably accessible (Zikmund, 1997).

(C) The International Journal of Indian Psychology, ISSN 2348-5396 (e) | ISSN: 2349-3429 (p) | 33 
Association between Happiness and Related Psychosocial Correlates and Job Satisfaction among the Employees of Information Technology (IT) Sector: A Comparative Analysis of Gender Difference

\section{Data Collection Tools And Measures:}

A) Level of happiness was measured using oxford happiness inventory (1980s). This inventory consisted of 29 items and each item having four incremental levels of response, numbered from 0 to 3 . The items receive the score same as the response given by the subjects, for e.g., response of 1 gets a score of 1 . The higher score denotes the higher level of happiness. The score ranges between $0-57$. The alpha reliability for the test is found to be 0.92 .

B) Inter-personal relationship was measured by applying interpersonal relationship inventory. The scale consisted of 39 items and these items are divided into 3 domains such as social support, reciprocity and conflict. The test retest reliability for one 2 weeks is found to be 0.91(social support), 0.84(reciprocity) and 0.81(conflict).

C) Coping was measured by coping checklist II (Rao et.al, 1989). The test retest reliability for a period of one month is 0.74 and the internal consistency is 0.76 .

D) Job satisfaction was measured using job satisfaction scale by B.C. Muthayya (1973). The scale consisted of 34 items. The answer categories for each of the items were agree (A), not sure (NS), disagree (D) and not applicable (NA). The split-half reliability coefficient of the scale is 0.81 . The score range is $0-68$.

\section{Statistical Tool:}

Descriptive statistics and correlation statistics were done using SPSS (version 16.0).

\section{TABLES AND RESULT}

Table-1: Showing the difference in mean (M), standard deviation (SD) and ' $t$ ' values between Male and Female IT sector employees for selected variables. $(n=50$, male=25, female=25).

\begin{tabular}{|c|c|c|c|c|c|}
\hline \multirow{2}{*}{ Variables } & \multicolumn{2}{|c|}{ Male } & \multicolumn{2}{c|}{ Female } & 't' Value \\
\cline { 2 - 5 } & $\mathbf{M}$ & Sd & M & Sd & \\
\hline Happiness & 58.08 & 6.82 & 54.32 & 7.27 & 1.88 \\
\hline $\begin{array}{c}\text { Interpersonal } \\
\text { Relationship }\end{array}$ & 129.96 & 9.01 & 129.52 & 6.05 & 0.203 \\
\hline Coping & 22.76 & 4.69 & 20.72 & 4.86 & 1.508 \\
\hline Job Satisfaction & 37.32 & 7.89 & 40.52 & 7.75 & 1.446 \\
\hline
\end{tabular}

$* * \mathbf{p}<0.01, * \mathbf{p}<0.05$

Table- 2: Showing the Product moment correlation coefficient value between job satisfaction and other variables for the total group.

\begin{tabular}{|c|c|}
\hline Variables & 'R' Value \\
\hline Happiness - Job Satisfaction & $\mathbf{0 . 0 2 5}$ \\
\hline Interpersonal Relationship - Job Satisfaction & $\mathbf{0 . 1 8 2}$ \\
\hline Coping - Job Satisfaction & $\mathbf{0 . 0 4 0}$ \\
\hline
\end{tabular}

${ }^{* *} \mathbf{p}<0.01, * \mathbf{p}<0.05$ 


\section{Association between Happiness and Related Psychosocial Correlates and Job Satisfaction among the Employees of Information Technology (IT) Sector: A Comparative Analysis of Gender Difference}

\section{DISCUSSION}

The Information Technology (IT) is one of the fastest growing sectors in the global scenario. India's IT industry is known for its massive turnover and its huge employment base. Current environment is the business environment as it is giving birth to the corporate advancement in the country. This sector is also becoming the part of the Indian economy as the tremendous growth of the IT sector over the past few years has resulted in considerable changes in the lives of its young workforce.

It is very clear that the world is flat due to information technology (IT). IT has agitated the world and brought about worldwide industry. However, based on the systems strategy triangle, a company has to balance its commerce, organizational and information system strategies to be booming. It is, consequently, not amazing that the job satisfaction among the IT employees is leading to the achievement of any commerce of these existence.

In the present study, an above average job satisfaction has been found among the employees of IT sector. The entire job satisfaction factors be relevant to IT employees presently as they do all employees: recompense, reimbursement, flexible hours, the presence of telecommute, having a excellent superior and delightful colleagues employees, having an opportunity to learn their skills, being acknowledged for the work and having opportunity to press forward within the organization (Nemani et.al, 2011).

In the present study, the female ale employees are found to be more satisfied to their job than the male employees. But it is must to indicate that the difference is between the mean is close to each other and the result reveals that there is no significant difference between the mean of male and female IT sector employees. Thus it is clear that the both group exposes the same level of job satisfaction to their job. This kind of result may be influenced by the benefit provided by the management authority equally for the both gender. These benefits includes Insurance, Health \& Wellness ( disability insurance, vision insurance, dental insurance etc.) ; life insurance; financial and retirement (pension plan, retirement plan, stock options and performance bonus); family and parenting benefits (Work From Home, Maternity \& Paternity Leave, Childcare, Reduced or Flexible Hours, Unpaid Extended Leave ); Vacation \& Time Off (vacation and paid time off, sick leave, bereavement leave); perks benefits; professional support; job security etc.

For the dimension of assessment of happiness the male employees are found to happier than the female employees but the significant difference between the two groups could not be established. Impact of some socio-cultural factor for this equality of responses may have been provided.

In case of interpersonal relationship and coping responses the two groups are not found to be differ significantly from each other. The quality of quality of interpersonal relationship was found as same among the both gender whereas, coping responses are found to be better in male employees than the female employees. 


\section{Association between Happiness and Related Psychosocial Correlates and Job Satisfaction among the Employees of Information Technology (IT) Sector: A Comparative Analysis of Gender Difference}

Job satisfaction is found to be related with several psycho-social variables in the previous research work but for the present research work it is found that job satisfaction is not significantly associated with level of happiness, interpersonal relationship and coping among the employees of present sample for investigation.

Thus, overall explanation of this section can be summarized into that IT sector employees of private sector are found to be satisfied to their job for the present study and their level of job satisfaction are not significantly associated with the other variables and furthermore there is no gender difference in happiness, interpersonal relationship, coping and job satisfaction among the IT sector employees. On the basis of the present findings it can be elaborate that there may have the effect of some cultural factors that helps to turn on the switch of job satisfaction among the employees of it sector which can be summarized into the following figure

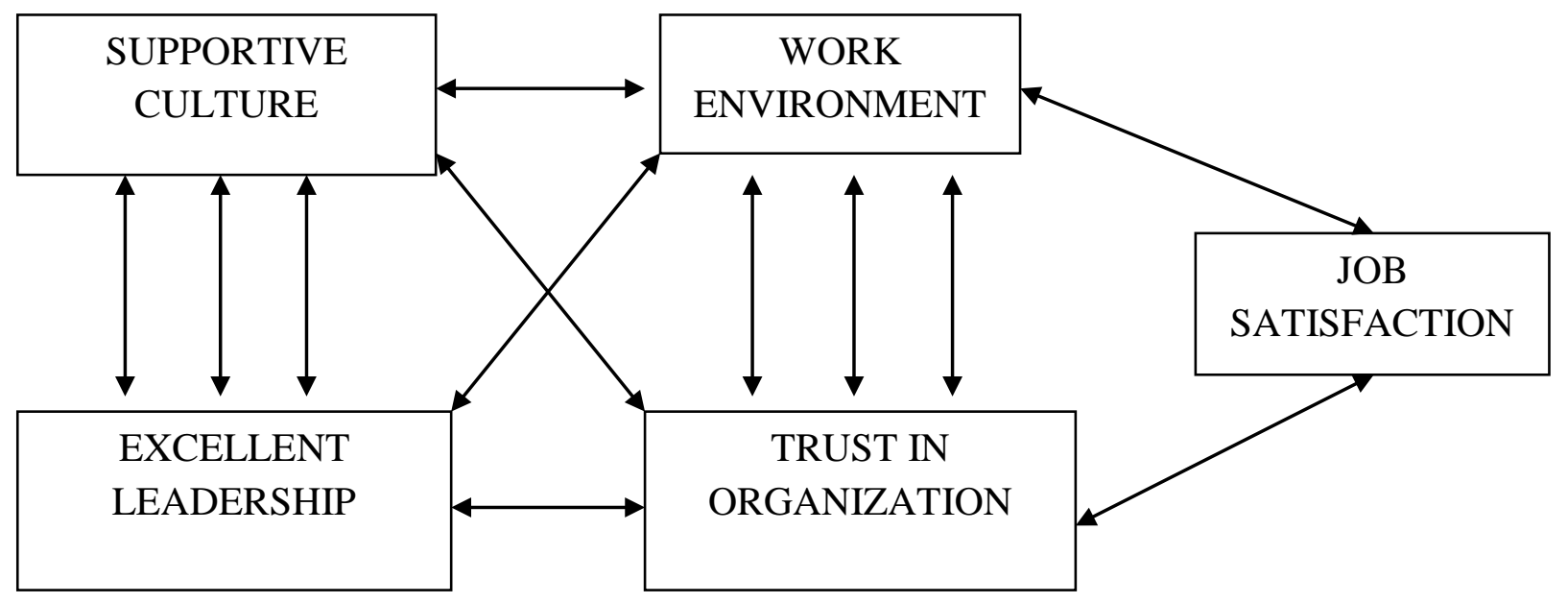

\section{CONCLUSION}

1. There is no significant difference between the male and female IT sector employees in level of happiness.

2. There is no significant difference between the male and female IT sector employees in quality of interpersonal relationship.

3. There is no significant difference between the male and female IT sector employees in coping style.

4. There is no significant difference between the male and female IT sector employees in level of job satisfaction.

5. There is no significant association between happiness and job satisfaction among the IT sector employees.

6. There is no significant association between interpersonal relationship and job satisfaction among the IT sector employees.

7. There is no significant association between coping and job satisfaction among the IT sector employees. 
Association between Happiness and Related Psychosocial Correlates and Job Satisfaction among the Employees of Information Technology (IT) Sector: A Comparative Analysis of Gender Difference

\section{Limitation Of The Study:}

$>$ Respondent's opinions are dynamic; they keep changing from time to time.

$>$ Some of the respondents might not have given the actual information due to fear of being disclosed.

$>$ The study was conducted with the limited number of respondent due to time constraint.

\section{Practical Implication:}

Findings of the study provide institutional leaders administrators, and human resources professionals with key information that would enable them to recruit, reward, promote, and retain male and female employees. The finding would also enable the governing body of company to address the issues concerning the gender aspects and job satisfaction accordingly that may affect the amount of productivity.

\section{Acknowledgments}

The author appreciates all those who participated in the study and helped to facilitate the research process.

\section{Conflict of Interests}

The author declared no conflict of interests.

\section{REFERENCES}

Bender, K. A., Donohue, S. M., \& Heywood, J. S. (2005). Job satisfaction and gender segregation. Oxford Economic Papers, 57, 479-496.

Creswell, J. W. (1994). Research designs: Qualitative and quantitative approaches. Thousand Oaks, CA: Sage.

Fields, D., \& Blum, T. C. (1997). Employee satisfaction in work groups with different gender composition. Journal of Organizational Behaviour, 18,181-196.

Flarencis LB, Lucia Madrigal and cermen pages (2010), 'part time work, gender and job satisfaction', journal of development studies 46(9): 1543-71

Graham, Michael C. (2014). Facts of Life: ten issues of contentment. Outskirts Press. pp. 6-10.

Hodson Randy (1989), 'Gender Differences in Job Satisfaction: Why Aren't Women More Dissatisfied?’ The Sociological Quarterly, 30:3:385-99.

Hulin, C. L., \& Judge, T. A. (2003). Job attitudes. In W. C. Borman, D. R. ligen, \& R. J. Klimoski (Eds.), Handbook of psychology: Industrial and organizational psychology (pp. 255-276). Hoboken, NJ: Wiley.

J Belsky, M Perry-Jenkin., \&Crouter (1985).The work-family interface and marital change across the transition to parenthood. Journal of Family Issues, 6, 205-20.

Locke, E.A. (1976). “The nature and causes of job satisfaction”, in Dunnette, M.D. (Ed.), Handbook of Industrial and Organizational Psychology, Rand McNally, Chicago, IL, pp.1297-1343.

(c) The International Journal of Indian Psychology, ISSN 2348-5396 (e)| ISSN: 2349-3429 (p) | 37 


\section{Association between Happiness and Related Psychosocial Correlates and Job Satisfaction among the Employees of Information Technology (IT) Sector: A Comparative Analysis of Gender Difference}

Metle, M. K. (2001). Education, job satisfaction and gender in Kuwait. International Journal of Human Resource Management, 12: 311-332.

Moorman, R.H. (1993). "The influence of cognitive and affective based job satisfaction measures on the relationship between satisfaction and organizational citizenship behavior". Human Relations 6: 759-776.

Pook, L. A., Füstös, J., \& Marian, L. (2003). The impact of gender bias on job satisfaction Components of job satisfaction and advancement in post-liberation Hungary, Poland, and Romania. Human Systems Management, 22(1): 37-50.

Sousa-Poza, Alfonso and Sousa-Poza, Andrés A. (2003) 'Gender Differences in Job Satisfaction in Great Britain, 1991-2000: Permanent or Transitory?’ Applied Economics Letters 10 (11): 691-694.

Spector, P.E. (1997). Job satisfaction: Application, assessment, causes and consequences. Thousand Oaks, CA: SAGE.

Tomaževič, N.; Seljak, J.; Aristovnik, A. (2014). "Factors Influencing Employee Satisfaction in the Police Service: The Case of Slovenia". Personnel Review 43 (2): 209-227.

Weiten, W. \& Lloyd, M.A. (2008) Psychology Applied to Modern Life (9th ed.). Wadsworth Cengage Learning.

Zikmund, W.R., (1997), Business Research Methods (5th Ed.), the Dryden Press, Fort Worth, Texas.

How to cite this article: P Singha (2016), Association between Happiness and Related Psychosocial Correlates and Job Satisfaction among the Employees of Information Technology (IT) Sector: A Comparative Analysis of Gender Difference, International Journal of Indian Psychology, Volume 3, Issue 4, No. 68, ISSN:2348-5396 (e), ISSN:2349-3429 (p), DIP:18.01.194/20160304, ISBN:978-1-365-39398-3 